\title{
Epigallocatechin-3-Gallate Promotes the in vitro Maturation and Embryo Development Following IVF of Porcine Oocytes
}

This article was published in the following Dove Press journal: Drug Design, Development and Therapy

\author{
Kangfa Huang' \\ Chengde $\mathrm{Li}^{1}$ \\ Fenglei $\mathrm{Gao}^{2}$ \\ Yushan Fan' \\ Fanwen Zeng' \\ Li Meng' \\ $\mathrm{Li} \mathrm{Li}{ }^{\prime}$
}

Shouquan Zhang'

Hengxi Wei ${ }^{\prime}$

'National Engineering Research Center for Breeding Swine Industry, Guangdong Provincial Key Laboratory of AgroAnimal Genomics and Molecular Breeding, College of Animal Science, South China Agricultural University, Guangzhou, 510642, People's Republic of China; ${ }^{2}$ Department of Tropical Agriculture and Forestry, College of Guangdong Agriculture Industry Business Polytechnic, Guangzhou, Guangdong, 5 I0507, People's Republic of China
Correspondence: Hengxi Wei National Engineering Research Center for Breeding Swine Industry, Guangdong Provincial Key Laboratory of Agro-Animal Genomics and Molecular Breeding, College of Animal Science, South China Agricultural University, Guangzhou, 5 I0642, People's Republic of China Tel +86-20-85284869

Email weihengxi@scau.edu.cn
Purpose: Epigallocatechin-3-gallate (EGCG) is a major ingredient of catechin polyphenols and exerts protective effects because of its strong antioxidant properties. As far as we know, there is still a lack of systematic research on the effects of EGCG on the in vitro maturation (IVM) and in vitro fertilization (IVF) of porcine oocytes. The present study aimed to determine the effects of EGCG on the IVM and IVF of porcine oocytes.

Methods: Porcine oocytes were treated with different concentrations of EGCG $(5,10$ and 20 $\mu \mathrm{M}$ ), and the cumulus cell expansion, oocyte maturation rate, reactive oxygen species (ROS), glutathione (GSH) and malondialdehyde (MDA) levels, total antioxidant capacity were determined. The mRNA expression levels of oxidative stress- and apoptosis-associated genes were determined by quantitative real-time PCR. The cleavage rate and blastocyst rate of oocytes after $10 \mu \mathrm{M}$ EGCG treatment during IVM and IVF were also evaluated.

Results: EGCG at 5, 10 and $20 \mu \mathrm{M}$ significantly promoted cumulus cell expansion, and EGCG at $10 \mu \mathrm{M}$ increased the oocyte maturation rate. EGCG $(10 \mu \mathrm{M})$ treatment reduced the ROS and MDA levels, while increased the antioxidant capacity and GSH concentrations in the mature oocytes. The qRT-PCR results showed that EGCG treatment up-regulated the mRNA expression of catalase, glutathione peroxidase and superoxide dismutase in the mature oocytes. In addition, EGCG treatment also decreased the mRNA expression levels of Bax and caspase- 3 and increased the Bcl-2 mRNA expression level in the mature oocytes. In addition, the cleavage rate and blastocyst rate of oocytes treated with $10 \mu \mathrm{M}$ EGCG during IVM and IVF were significantly higher than those of the control group.

Conclusion: Our results suggest that EGCG promotes the in vitro maturation and embryo development following IVF of porcine oocytes. The protective effects of EGCG on the oocytes may be associated with its antioxidant and anti-apoptosis properties.

Keywords: EGCG, porcine oocytes, IVM, antioxidant, anti-apoptosis, IVF

\section{Introduction}

The in vitro maturation (IVM) of the oocytes is a key step in the in vitro production of embryos for the livestock. ${ }^{1,2}$ Oocytes from IVM have the capacity in fertilization and developing into embryos, while the successful rate for embryo development from IVM oocytes is lower than that from in vivo-maturated oocytes. ${ }^{3}$ The maturation of the oocytes requires both cytoplasmic and nuclear maturation, and incorrect cytoplasmic maturation has been suggested to contribute the poor developmental potential of IVM oocytes. ${ }^{3}$ Based on the previous studies, proper medium composition and culture conditions are essential for successful oocyte IVM. ${ }^{4}$ 
Epigallocatechin-3-gallate (EGCG) is one of the major bioactive compounds in green tea and belongs to the catechin polyphenols. ${ }^{5}$ EGCG has been well-known for its role in chelating the transition metals and thus to decrease the oxidative stress level. ${ }^{5}$ In vitro and in vivo experimental studies have shown that EGCG possess various biological functions including prevention of chromosomal damage by reactive oxygen species (ROS), antibacterial activities, anti-tumor activities and inhibition of lipogenesis. ${ }^{5}$ In the IVM oocytes, Huang et al showed that EGCG in the IVM medium could reduce ROS level and apoptosis in bovine oocytes and increase the cumulus cell expansion. ${ }^{6}$ Roth et al showed that intraperitoneal injection of the antioxidant EGCG improves developmental competence and the quality of the embryos that develop from hyperthermia-treated oocytes in mice. ${ }^{7}$ Gadani et al showed that supplementation of EGCG to thawed boar sperm improved the in vitro fertilization (IVF). ${ }^{8,9}$ However, a recent study by Bucci et al demonstrated that EGCG supplementation to thawing medium failed to improve dog sperm quality or zona binding capacity. ${ }^{10}$

As far as we know, there is still a lack of systematic research on the effects of EGCG on the IVM and IVF of porcine oocytes. Whether EGCG can be used as an effective antioxidant for porcine oocytes cultured in vitro remains to be explored. The effects of EGCG on the IVM and IVF of porcine oocytes were systematically investigated. In addition, ROS level, antioxidant capacity, antioxidant- and apoptosis-associated gene mRNA expression levels in oocytes were determined by the in vitro assays.

\section{Materials and Methods}

\section{Ethics Statement}

This work was approved by the Ethics Committee on Animal Experimentation of South China Agricultural University.

\section{EGCG Treatment}

The EGCG compound was purchased from Sigma-Aldrich (St. Louis, USA) and was prepared as $1 \mathrm{mM}$ stock concentration using M-199 medium (Sigma-Aldrich). To determine the effect of EGCG on the cumulus expansion index and in vitro maturation rate of the oocytes, and the ROS production of oocytes, different concentrations of EGCG $(0,5,10$ and 20 $\mu \mathrm{M})$ were supplemented to IVM medium (M-199 medium supplemented with $10 \%$ fetal bovine serum, $10 \%$ porcine follicular fluid, $0.57 \mathrm{mM}$ cysteine, $10 \mathrm{ng} / \mathrm{mL}$ epidermal growth factor, $10 \mathrm{IU} / \mathrm{mL}$ pregnant mare serum gonadotrophin and 10
$\mathrm{IU} / \mathrm{mL}$ human chorionic gonadotrophin). To determine the effects of EGCG on the total antioxidant capacity, glutathione (GSH) content, malondialdehyde (MDA) level and mRNA expression levels, EGCG $(0$ and $10 \mu \mathrm{M})$ was supplemented to the IVM medium. To determine the effects of EGCG on the developmental potential of the oocytes, EGCG $(0$ and $10 \mu \mathrm{M})$ were supplemented during IVM and/or IVF, or during IVM and/or IVC.

\section{Oocyte Collection and in vitro Maturation}

Ovaries were obtained from juvenile pigs slaughtered at a local slaughterhouse (Guangzhou Kongwangji Slaughterhouse, Guangzhou, China) and transferred to the laboratory in $0.9 \%$ saline at $37^{\circ} \mathrm{C}$ within $2 \mathrm{~h}$. Follicular fluid from 3-8 mm antral follicles was aspirated by a syringe with an 18-gauge needle attached. As previously described, ${ }^{11}$ approximately 50 cumulus oocyte complexes (COCs) were cultured in $500 \mu \mathrm{L}$ of (IVM) medium, covered with mineral oil and cultured for 44 h at $38.5^{\circ} \mathrm{C}$ in a $5 \% \mathrm{CO}_{2}$ incubator with humidified air.

\section{Assessment of Cumulus Expansion and IVM of Oocytes}

Cumulus expansion was recorded at $44 \mathrm{~h}$ of IVM. The assessment was blinded to eliminate bias. The degree of cumulus expansion for each COC was assessed according to a subjective scoring system on a scale of $0-4$, where 0 indicates no expansion, 1 indicates the minimal expansion observable, 2 indicates expansion of the outer cumulus cell layers, 3 indicates expansion of all cumulus cell layers except the corona radiata and 4 indicates complete expansion of all cumulus cell layers. ${ }^{12}$ The average score $(0.0-4.0)$ for each group, in each replicate (4-6 replicates), was then calculated to obtain a value referred to as the cumulus expansion index. The extrusion of the first polar body in the oocytes were determined under a light microscope. Oocytes were classified as follows: immature (did not reach metaphase), mature (presented a metaphase II plate and the polar body), and abnormal (any chromosomal aberrations such as diploid, abnormal metaphase II, multidirectional spindle, and chromosomal dispersion). The oocyte maturation rate was calculated as follows: number of matured oocytes/total oocytes examined x $100 \%$.

\section{Determination of ROS Levels}

To determine the intracellular ROS content, 30 mature oocytes were incubated for $20 \mathrm{~min}$ at $38.5^{\circ} \mathrm{C}$ in phosphate 
buffered saline (PBS) containing $10 \quad \mu \mathrm{M} \quad 2^{\prime}, 7^{\prime}$ dichlorofluorescein diacetate fluorescent probe (Beyotime Biotechnology, Shanghai, China) in the dark. The oocytes were then washed with PBS supplemented with $1 \%$ bovine serum albumin. Images were captured by a confocal microscopy system (IX71, Olympus, Japan) with the same scanning settings among groups. Fluorescence intensity was calculated with ImageJ software.

\section{Total Antioxidant Capacity Assay}

The total antioxidant capacity in the oocytes were analyzed using Total Antioxidant Capacity Assay Kit with ABTS method (Beyotime, Beijing, China) according to the manufacturer's protocol. The ABTS test measures the total antioxidant capacity of a sample and it is based on the ABTS • + radical discoloration. The cationic radical ABTS $\bullet+$ is a chromophore that absorbs at a wavelength of $734 \mathrm{~nm}$ and is generated by an oxidation reaction of ABTS (2,2'-azino-bis- (3-ethylbenzthiazolin-6-ammonium sulfonate) with potassium persulfate. ${ }^{13}$

\section{Quantification of GSH Content}

GSH content was measured using the Total Glutathione Assay Kit (S0053, Beyotime, Beijing, China) according to the manufacturer's instructions. This kit employs a kinetic enzymatic recycling assay, based on the oxidation of GSH by 5,5'-dithiobis-(2-nitrobenzoic acid), [DTNB] to measure the total glutathione (tGSH) content of biological samples. Glutathione standards or treated samples are added to the microtiter plate wells, followed by DTNB and glutathione reductase. Addition of $\mathrm{NADPH}_{2}$ to the wells initiates the progressive reduction of DTNB by GSH, causing a color increase that is monitored at $405 \mathrm{~nm}$. Briefly, the samples were seeded into 96-well plates, and then $150 \mu \mathrm{L}$ of detection solution was added to each well. After the samples were equilibrated at room temperature for $5 \mathrm{~min}, 50 \mu \mathrm{L}$ of a $0.16 \mathrm{mg} / \mathrm{mL}$ NADPH solution was added. GSH content was determined by dividing the measured value of 5-thio-2-nitrobenzoic acid by the number of oocytes in each sample.

\section{Quantification of Malondialdehyde (MDA) Level}

The MDA level in the oocytes were analysed using MDA assay kit (Beyotime) according to the manufacturer's protocol. MDA reacts with thiobarbituric acid (TBA) to give a red compound which has a maximum absorbance at $532 \mathrm{~nm}$. TBA reagent was prepared by mixing $0.2 \mathrm{~mL}$ SDS (8.1\%), $1.5 \mathrm{~mL}$ acetic acid $(20 \%, \mathrm{pH}=3.5)$ and $1.5 \mathrm{~mL} \mathrm{TBA}(0.8 \%)$ together, then $100 \mu \mathrm{L}$ of each homogenized oocyte samples was mixed with this $200 \mu \mathrm{L}$ TBA reagent. The mixture was incubated in a boiling water bath for $15 \mathrm{~min}$ and then cooled on ice. After cooling, the mixture centrifuged at $4000 \mathrm{rpm}$ for 10 mins. The absorbance of supernatant was determined at 532 nm against a blank.

\section{In vitro Fertilization and Embryo Culture}

The IVF experiment was conducted as previously reported. ${ }^{14}$ Briefly, oocytes collected from the local slaughterhouse were cultured for $44 \mathrm{~h}$ and denuded in $1 \mathrm{mg} / \mathrm{mL}$ hyaluronidase in DPBS by mechanically pipetting; then, 10-15 oocytes were grouped and transferred to the $50 \mu \mathrm{L}$ mTBM fertilization medium (113.1 mM NaCl, $3.0 \mathrm{mM} \mathrm{KCl}, 7.5 \mathrm{mM} \mathrm{CaCl}_{2} \cdot 2 \mathrm{H}_{2}$ $\mathrm{O}, 20.0 \mathrm{mM}$ Tris, $11.0 \mathrm{mM}$ glucose, $5.0 \mathrm{mM}$ sodium pyruvate) containing $2.5 \mathrm{mM}$ caffeine and $2 \mathrm{mg} / \mathrm{mL} \mathrm{BSA} \mathrm{(frac-}$ tion $\mathrm{V}$ ) covered with mineral oil. The fresh semen (from the Duroc pig with $\sim 12$ months old and a history of multiple breeding) provided by the Guangxi Yangxiang Company Co. Ltd (Guangxi, China) was washed three times by centrifugation with DPBS supplemented with $0.1 \%$ BSA at $1500 \mathrm{rpm}$ for $4 \mathrm{~min}$. The spermatozoa pellets were resuspended and diluted to $1 \times 10^{6}$ sperm $/ \mathrm{mL}$ with $\mathrm{mTBM}$ for capacitation in the $\mathrm{CO}_{2}$ incubator for $30 \mathrm{~min}$. Then, the capacitated sperm were added to the drop containing oocytes with a final sperm concentration of $1 \times 10^{5} \mathrm{sperm} / \mathrm{mL}$ and co-incubated for $6 \mathrm{~h}$ at $39{ }^{\circ} \mathrm{C}$ in an atmosphere of $5 \% \mathrm{CO}_{2}$ in air. After fertilization, the oocytes were washed 3 times with PZM3 medium and cultured with PZM3 medium at $39{ }^{\circ} \mathrm{C} ; 5 \% \mathrm{O}_{2}, 5 \% \mathrm{CO}_{2}$, and $90 \% \mathrm{~N}_{2}$; and $100 \%$ humidity. Embryonic cleavage and blastocyst formation were assessed at $48 \mathrm{~h}$ and 6 days after insemination, respectively. The formulas for assessing the cleavage and blastocyst rates were as follow: cleavage rate $=$ number of cleavage/number of matured oocytes; blastocyst rate $=$ number of blastocyst/number of matured oocytes.

\section{Quantitative Real-Time PCR (qRT-PCR)}

Total RNA was extracted from the matured oocytes using Trizol reagent (Invitrogen, USA), and quantified by measuring the absorbance at $260 \mathrm{~nm}$. The RNA was reversely transcribed into cDNA using the HiScript ${ }^{\circledR}$ III RT SuperMix kit (Vazyme, Nanjing, China). The real-time PCR was performed on an qTOWER ${ }^{3}$ thermal cycler (Analytik Jena, Germany) using ChamQ ${ }^{\mathrm{TM}}$ Universal SYBR $^{\circledR}$ qPCR Master Mix kit (Vazyme). The mRNA expression levels of the detected genes were normalized by GAPDH, and were calculated using the $2^{-\Delta \Delta \mathrm{Ct}}$ method. The sequences of the primers were shown in Supplemental Table S1. 


\section{Statistical Analysis}

All the data analysis was performed using the R Statistical Software (Version 3.6.3). All the data were presented as mean \pm standard deviation. Significant differences between different treatment groups were evaluated using Permutation tests. $\mathrm{P}<0.05$ was considered statistically significant.

\section{Results}

\section{Effects of EGCG on the Cumulus Expansion Index}

The morphology of the mature oocytes and oocytes with the first polar body extrusion was shown in Supplemental Figure S1A and S1B, respectively. Firstly, we examined the cumulus expansion index in the oocytes after being treated with different concentrations of EGCG, and as shown in Table 1, EGCG at 5 and $10 \mu \mathrm{M}$ significantly increased the cumulus expansion index when compared to the control group $(5 \mu \mathrm{M}$ group versus $0 \mu \mathrm{M}$ group: 2.989 \pm 0.068 versus $2.438 \pm 0.081 ; 10 \mu \mathrm{M}$ group versus $0 \mu \mathrm{M}$ group: $3.079 \pm 0.110$ versus $2.438 \pm 0.081$ ). However, EGCG at $20 \mu \mathrm{M}$ had no effect on the cumulus expansion index when compared to the control group (20 $\mu \mathrm{M}$ group versus $0 \mu \mathrm{M}$ group: $2.879 \pm 0.076$ versus $2.438 \pm 0.081$ ).

\section{Effects of EGCG on IVM Rate of the Oocytes}

The effects of EGCG on the in vitro maturation rate of the oocytes were further determined. As shown in Table 2, the oocyte maturation rate was higher in the 5 and $20 \mu \mathrm{M}$ group when compared to the $0 \mu \mathrm{M}$ EGCG control group; while the difference was not statistically significant (Table 2). On the other hand, $10 \mu \mathrm{M}$ EGCG treatment significantly increased the oocyte maturation rate when compared to the $0 \mu \mathrm{M}$ EGCG control group (10 $\mu \mathrm{M}$ group versus $0 \mu \mathrm{M}$ group: $58.63 \pm 2.79 \%$ versus $46.27 \pm 3.25 \% ; \mathrm{P}<0.05)$.

Table I Effects of EGCG on the Cumulus Expansion Index

\begin{tabular}{|l|c|c|}
\hline $\begin{array}{l}\text { EGCG } \\
(\mu \mathrm{M})\end{array}$ & $\begin{array}{c}\text { Number of } \\
\text { Oocytes }\end{array}$ & $\begin{array}{c}\text { Cumulus Expansion } \\
\text { Index }\end{array}$ \\
\hline 0 & 221 & $2.438 \pm 0.081^{\mathrm{b}}$ \\
5 & 220 & $2.989 \pm 0.068^{\mathrm{a}}$ \\
10 & 231 & $3.079 \pm 0.110^{\mathrm{a}}$ \\
20 & 226 & $2.879 \pm 0.076^{\mathrm{a}, \mathrm{b}}$ \\
\hline
\end{tabular}

Notes: The experiments were repeated for four times, and each group had $\sim 50$ oocytes for each replicate. Different superscript letters in the same column indicates statistically significant difference $(P<0.05)$.
Table 2 Effects of EGCG on the in vitro Maturation Rate of the Oocytes

\begin{tabular}{|l|c|c|c|}
\hline $\begin{array}{l}\text { EGCG } \\
(\boldsymbol{\mu M})\end{array}$ & $\begin{array}{c}\text { Number of } \\
\text { Oocytes }\end{array}$ & $\begin{array}{c}\text { Extrusion of the } \\
\text { First Polar Body }\end{array}$ & $\begin{array}{c}\text { Oocyte } \\
\text { Maturation } \\
\text { Rate }\end{array}$ \\
\hline 0 & 568 & 262 & $46.27 \pm 3.25^{\mathrm{b}}$ \\
5 & 604 & 328 & $54.43 \pm 1.85^{\mathrm{b}}$ \\
10 & 621 & 364 & $58.63 \pm 2.79^{\mathrm{a}}$ \\
20 & 579 & 300 & $51.85 \pm 2.64^{\mathrm{b}}$ \\
\hline
\end{tabular}

Notes: The experiment was repeated for 6 times, and each group had 50-150 oocytes for each replicate. Different superscript letters in the same column indicates statistically significant difference $(P<0.05)$.

\section{Effects of EGCG on Oxidative Stress of the Oocytes}

The ROS production of the EGCG-treated oocytes was determined by the ROS production assay. The representative images of the ROS fluorescent signals in oocytes after treatment with different concentrations of EGCG were shown in Figure 1A. The quantification of the immunofluorescent staining showed that EGCG at $5 \mu \mathrm{M}$ failed to affect the ROS production in the oocytes when compared to $0 \mu \mathrm{M}$ control group (Figure $1 \mathrm{~B}$ ). EGCG at 10 and 20 $\mu \mathrm{M}$ significantly reduced ROS levels of the oocytes when compared to the $0 \mu \mathrm{M}$ EGCG control group (Figure 1B).

As EGCG at $10 \mu \mathrm{M}$ could increase the cumulus expansion index and oocyte maturation rate, and also reduce the ROS level in the oocytes, EGCG at $10 \mu \mathrm{M}$ was chosen for the subsequent studies. As shown in Figure 1C, EGCG at $10 \mu \mathrm{M}$ significantly increased the antioxidant capacity of the oocytes when compared to the $0 \mu \mathrm{M}$ control group (Figure 1C). In addition, the level of glutathione was increased while the level of MDA was decreased in the oocytes treated with $10 \mu \mathrm{M}$ EGCG (Figure 1D and E).

Furthermore, the qRT-PCR was performed to the determine the mRNA expression levels of the oxidative stressrelated genes including catalase (CAT), glutathione peroxidase (GPx) and superoxide dismutase (SOD). EGCG at $10 \mu \mathrm{M}$ significantly up-regulated the mRNA expression levels of CAT, GPx and SOD when compared to the $0 \mu \mathrm{M}$ control group (Figure 2A-C).

\section{Effects of EGCG on the mRNA Expression Levels of Apoptosis-Related Genes in the Oocytes}

The qRT-PCR was performed to the determine the mRNA expression levels of apoptosis-related genes including 
A

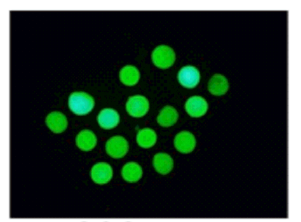

EGCG $(0 \mu \mathrm{M})$

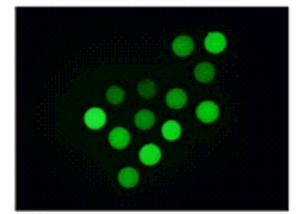

$\operatorname{EGCG}(10 \mu \mathrm{M})$

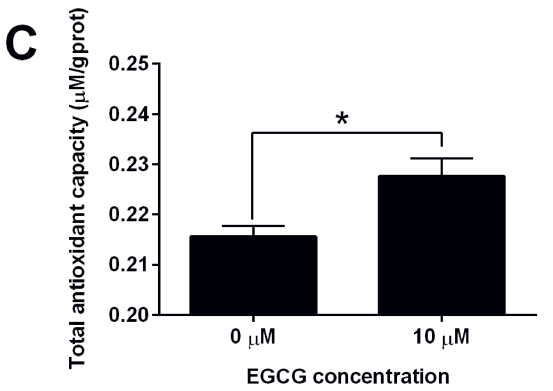

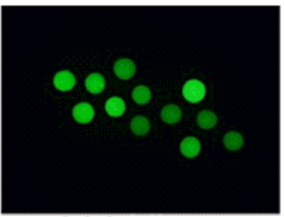

EGCG $(5 \mu \mathrm{M})$

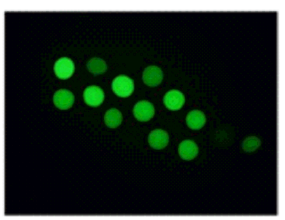

EGCG $(20 \mu \mathrm{M})$
B

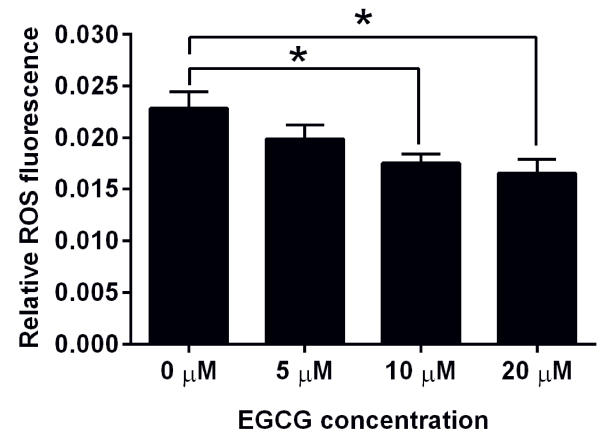

Figure I Effects of EGCG on the oxidative stress in the matured porcine oocytes. (A) The representative images of the ROS fluorescent signals in oocytes after treatment with different concentrations of EGCG. (B) The effects of EGCG on the ROS production of oocytes. The effects of EGCG on the antioxidant capacity (C), glutathione concentration (D) and MDA concentration (E) in the matured oocytes were determined by respective in vitro assays. $N=3$; significant differences were indicated as $* \mathrm{P}<0.05$.
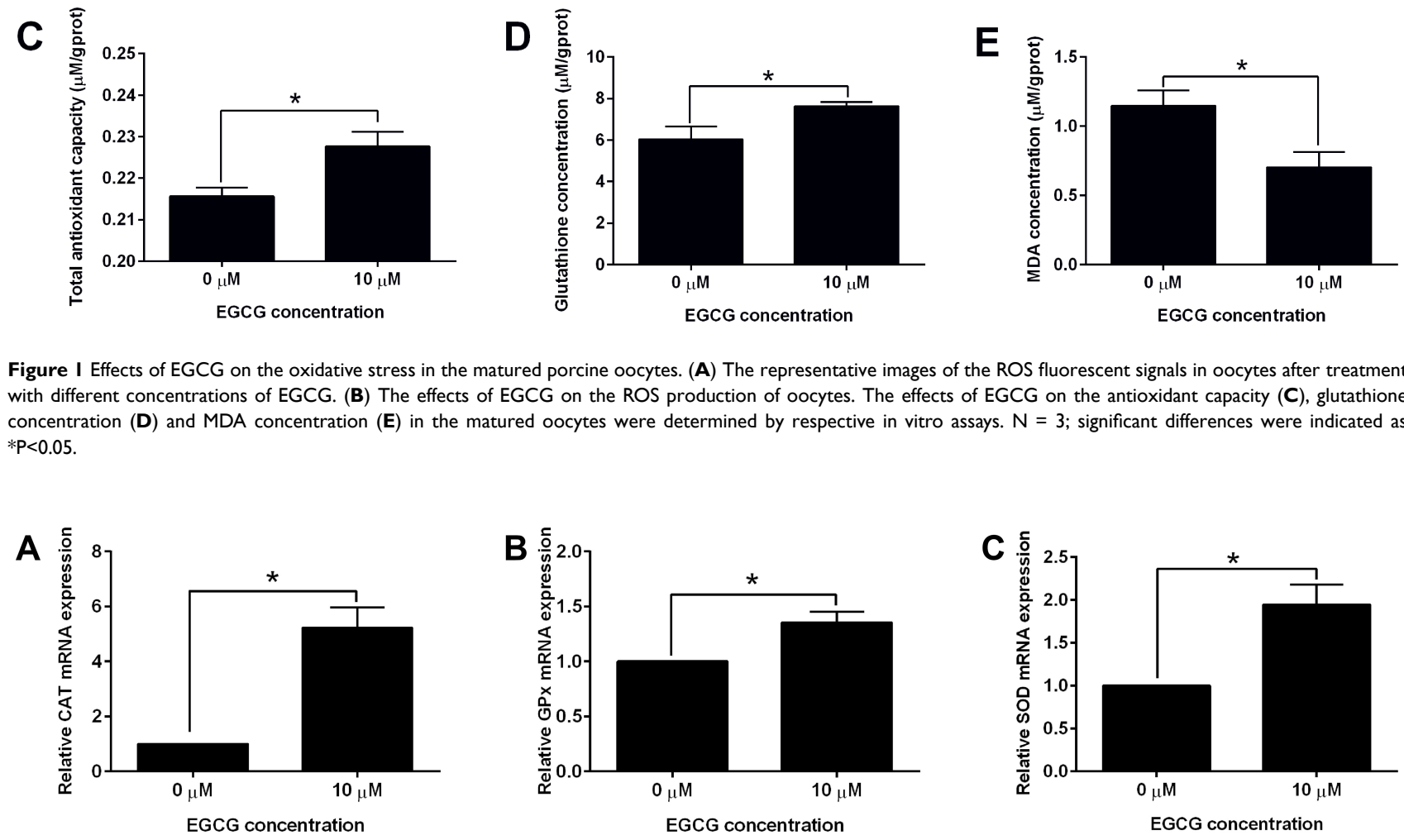

Figure 2 The effects of EGCG on the oxidative stress-related genes. (A) CAT, (B) GPx and (C) SOD mRNA expression levels of the matured oocytes after EGCG treatment were determined by $\mathrm{QRT}$-PCR. $\mathrm{N}=3$; significant differences were indicated as $* \mathrm{P}<0.05$.

Bax, Bcl-2 and caspase-3. EGCG at $10 \mu \mathrm{M}$ significantly decreased the mRNA expression levels of Bax and caspase-3, and increased the mRNA expression level of Bcl-2 when compared to the $0 \mu \mathrm{M}$ control group (Figure $3 \mathrm{~A}-\mathrm{C}$ ).

\section{Effects of EGCG Used During IVM and IVF on the Developmental Potential of the Oocytes}

The representative images for the embryos and blastocysts were shown in Supplemental Figure S1C-S1E. EGCG treatment during IVF significantly increased the cleavage rate and blastocyst rate when compared to the control group (Table 3). EGCG treatment during IVM significantly increased the blastocyst rate, but not the cleavage rate when compared to the control group (Table 3). Moreover, EGCG treatment during both IVM and IVC significantly increased the cleavage rate and blastocyst rate when compared to the other three groups (Table 3). These results indicated that EGCG during IVM and IVF could promote the developmental potential of oocytes. 

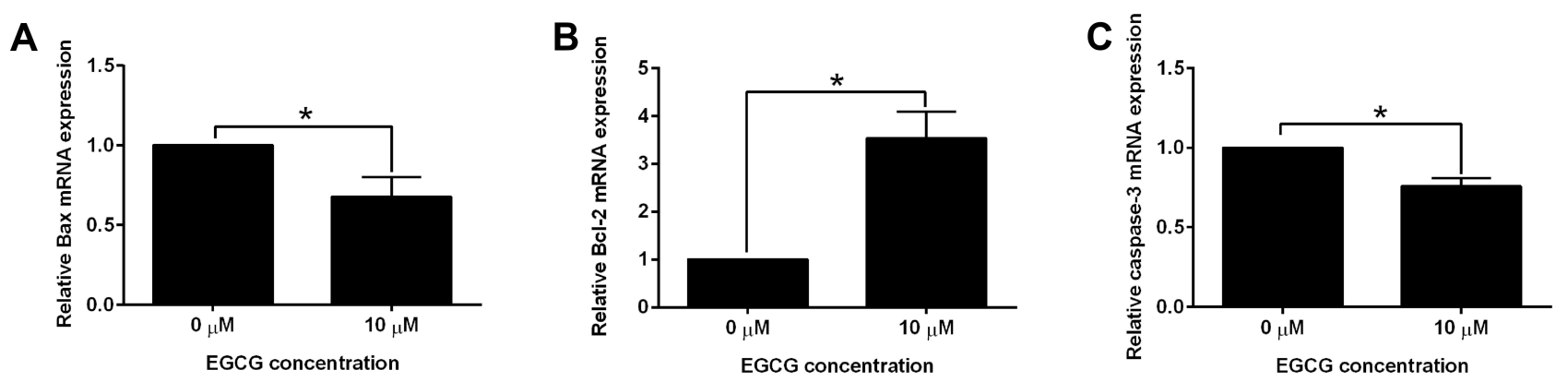

Figure 3 The effects of EGCG on the apoptosis-related genes. (A) Bax, (B) Bcl-2 and (C) caspase-3 mRNA expression levels of the matured oocytes after EGCG treatment were determined by qRT-PCR. $\mathrm{N}=3$; significant differences were indicated as $* \mathrm{P}<0.05$.

\section{Effects of EGCG Used During IVM and IVC on the Developmental Potential of the Oocytes}

EGCG treatment during IVC significantly reduced the cleaved rate and blastocyst rate of the oocytes when compared to the group without EGCG treatment (Table 4). On the other hand, EGCG treatment during IVM significantly increased the cleavage rate and blastocyst rate of the oocytes when compared to the group without EGCG treatment (Table 4). EGCG treatment during IVM and IVC significantly decreased the cleavage rate and blastocyst rate of the oocytes when compared to the group without EGCG treatment and group with EGCG treatment during IVM (Table 4). Collectively, these results indicated that EGCG treatment during IVM increased the oocyte developmental potential while EGCG treatment during IVC attenuated the oocyte developmental potential.

\section{Discussion}

The IVM technique for the COC has been developed and applied to produce offspring in mammals including pigs, however, the rate of blastocytes formation following IVF is still low using IVM oocytes compared with that of in vivo-matured oocytes such as pigs. ${ }^{15}$ In pigs, the COCs are usually collected from medium size antral follicles ( $>3 \mathrm{~mm}$ diameter) where the oocyte has the ability to induce oocyte maturation, whereas follicular somatic cells do not acquire the ability to respond to ovulation stimuli. In addition, in vitro environments usually increase cell production of ROS, which has been implicated as a main cause of cell damage. ${ }^{16}$ Therefore, optimizing the culture conditions to mimic the in vivo environments is essential for the normal growth and maturation of oocytes. In the present study, different concentrations of EGCG were added to the culture medium of IVM, IVF and IVC to

Table 3 Effects of EGCG Used During IVM and IVF on the Developmental Potential of the Oocytes

\begin{tabular}{|l|c|c|c|c|c|c|}
\hline $\begin{array}{l}\text { EGCG }(\boldsymbol{\mu M}) \\
\text { During IVM }\end{array}$ & $\begin{array}{c}\text { EGCG }(\boldsymbol{\mu M}) \\
\text { During IVF }\end{array}$ & $\begin{array}{c}\text { Number of Mature } \\
\text { Oocytes }\end{array}$ & $\begin{array}{c}\text { Number of } \\
\text { Cleaved Oocytes }\end{array}$ & $\begin{array}{c}\text { Cleavage } \\
\text { Rate (\%) }\end{array}$ & $\begin{array}{c}\text { Number of } \\
\text { Blastocysts }\end{array}$ & $\begin{array}{c}\text { Blastocyst } \\
\text { Rate (\%) }\end{array}$ \\
\hline 0 & 0 & 214 & 90 & $42.34 \pm 1.76^{\mathrm{c}}$ & 48 & $22.01 \pm 2.66^{\mathrm{c}}$ \\
0 & 10 & 241 & 108 & $56.58 \pm 4.19^{\mathrm{b}}$ & 61 & $30.91 \pm 1.24^{\mathrm{b}}$ \\
10 & 0 & 122 & 55 & $45.37 \pm 3.40^{\mathrm{c}}$ & 33 & $26.81 \pm 2.28^{\mathrm{b}}$ \\
10 & 10 & 144 & 86 & $59.76 \pm 3.96^{\mathrm{a}}$ & 51 & $35.29 \pm 1.72^{\mathrm{a}}$ \\
\hline
\end{tabular}

Note: Different superscript letters in the same column indicates statistically significant difference $(P<0.05)$.

Table 4 Effects of EGCG Used During IVM and IVC on the Developmental Potential of the Oocytes

\begin{tabular}{|l|c|c|c|c|c|c|}
\hline $\begin{array}{l}\text { EGCG }(\boldsymbol{\mu M}) \\
\text { During IVM }\end{array}$ & $\begin{array}{c}\text { EGCG }(\boldsymbol{\mu M}) \\
\text { During IVC }\end{array}$ & $\begin{array}{c}\text { Number of Mature } \\
\text { Oocytes }\end{array}$ & $\begin{array}{c}\text { Number of } \\
\text { Cleaved Oocytes }\end{array}$ & $\begin{array}{c}\text { Cleavage } \\
\text { Rate (\%) }\end{array}$ & $\begin{array}{c}\text { Number of } \\
\text { Blastocysts }\end{array}$ & $\begin{array}{c}\text { Blastocyst } \\
\text { Rate (\%) }\end{array}$ \\
\hline 0 & 0 & 199 & 84 & $40.98 \pm 2.71^{\mathrm{b}}$ & 52 & $25.37 \pm 3.58^{\mathrm{b}}$ \\
0 & 10 & 223 & 72 & $31.46 \pm 5.72^{\mathrm{c}}$ & 44 & $19.63 \pm 2.23^{\mathrm{c}}$ \\
10 & 0 & 165 & 82 & $48.28 \pm 2.3^{\mathrm{a}}$ & 52 & $30.23 \pm 3.05^{\mathrm{a}}$ \\
10 & 10 & 172 & 52 & $28.02 \pm 4.60^{\mathrm{c}}$ & 33 & $17.96 \pm 2.46^{\mathrm{c}}$ \\
\hline
\end{tabular}

Note: Different superscript letters in the same column indicates statistically significant difference $(P<0.05)$. 
observe the maturation quality of oocytes. EGCG at 10 $\mu \mathrm{M}$ significantly improve the IVM of porcine oocytes. In this study, the supplementation of EGCG during IVF and IVC produces two different effects. Supplementation of 10 $\mu \mathrm{M}$ EGCG during IVF can promote the cleavage rate of oocytes, which was consistent with findings from Spinaci et al, showing that supplementation of $10 \mu \mathrm{M}$ EGCG during IVF but not IVM significantly increased the fertilization rate. ${ }^{17}$ The effect of the addition of EGCG during IVF could be due to its action on the sperm not on the oocyte.

In the process of in vitro culture, oocytes and embryos are inevitably exposed to light and higher oxygen concentration than in vivo, which may lead to enhanced production of ROS (superoxide anion, hydrogen peroxide and highly reactive hydroxyl). A large number of studies have shown that the supplementation of antioxidants to the IVM medium can improve the developmental ability of the embryo. EGCG acts as antioxidant has been found to moderate the deleterious effects of maternal hyperthermia on follicle-enclosed oocytes in mice. ${ }^{7}$ Barberino et al demonstrated that EGCG attenuated apoptosis of preantral follicles through the phosphatidylinositol-3-kinase/protein kinase B signaling pathway after in vitro culture of sheep ovarian tissue. ${ }^{18}$ Huang et al suggested that $50 \mu \mathrm{M}$ EGCG can improve the bovine oocyte maturation, and the protective role of EGCG may be correlated with its antioxidative property. ${ }^{6}$ In combination with previous studies, our results indicated that the effects of EGCG on the IVM of porcine oocytes may be related to the antioxidant and antiapoptosis effect, which was further explored in the present study.

Excessive accumulation of ROS can lead to oxidative stress, and our results showed that EGCG can increase the total antioxidant capacity and reduce the level of ROS and MDA in the porcine oocytes. This may be due to that EGCG can directly eliminate ROS and/or EGCG can act synergistically with the antioxidant system. ${ }^{5}$ Non-enzymatic systems rely on molecules to directly quench ROS, while enzymatic systems are composed of specific enzymes that detoxify ROS. In the latter, the SOD family is important in the regulation of oxidative stress. SOD is the only known enzyme that directly scavenges free radicals by catalyzing the dismutation of superoxide anion to hydrogen peroxide. SOD enzyme regulates the levels of superoxide and hydrogen peroxide produced by cells, and then regulates cell signal transduction. ${ }^{19}$ Catalase is an important antioxidant and a marker enzyme of peroxisomes. It accounts for $40 \%$ of the total peroxisome enzymes. It is an antioxidant oligomerase with four identical subunits arranged in tetrahedrons, and is an important enzyme that protects cells from ROS oxidative damage. ${ }^{20}$ Glutathione is a tripeptide composed of glutamic acid, cysteine and glycine containing $\gamma$-amide bonds and sulfhydryl groups. It can maintain the normal immune system function and has an antioxidant effect. Glutathione peroxidase (GPXs) combines GSH oxidation with $\mathrm{H}_{2} \mathrm{O}_{2}$ detoxification. $^{21}$ Studies demonstrated that heat stress could produce oxidative stress in bubaline oocytes, which triggers the elimination of ROS by the antioxidant enzyme defense system. ${ }^{22}$ Our studies consistently showed that EGCG reduced the ROS level and MDA content of the oocytes, while increased the intracellular GSH content and total antioxidant capacity.

The apoptosis process can affect the quality and survival rate of the oocytes and thus to influence the embryonic development. ${ }^{23}$ Bcl-2 family proteins play a key role in regulating cell death through the balanced interaction between pro-apoptotic and anti-apoptotic protein members. ${ }^{24}$ The pro-apoptotic protein Bax is the core of mammalian mitochondrial-dependent apoptosis. Caspase-3 also plays an irreplaceable role in cell apoptosis. Caspase-3 is the most important terminal splicing enzyme in the process of cell apoptosis, and activated caspase-3 is the key executor of cell apoptosis. Our results showing that EGCG up-regulated the $\mathrm{Bcl}-2$ mRNA expression level, but decreased Bax and caspase-3 mRNA expression levels. Collectively, these results implied that the antioxidant and anti-apoptotic effects of EGCG in porcine oocytes are largely related to the regulation of SOD1, CAT and GPX as well as the apoptosis-related genes.

In summary, our results suggest that EGCG promotes the in vitro maturation and embryo development following IVF of porcine oocytes. The protective effects of EGCG on the oocytes may be associated with its antioxidant and anti-apoptosis properties.

\section{Funding}

This study was supported by grants from the Natural Science Foundation of Guangdong Province (2020A1515010976), the Local Innovative and Research Teams Project of Guangdong Pearl River Talents Program (2019BT02N630), the Science and Technology Innovation Strategy Projects of Guangdong Province (2018B020203002). 


\section{Disclosure}

The authors report no conflicts of interest in this work.

\section{References}

1. Abdelnour SA, Abd El-Hack ME, Swelum AA, et al. The usefulness of retinoic acid supplementation during in vitro oocyte maturation for the in vitro embryo production of livestock: a review. Animals. 2019;9(8). doi:10.3390/ani9080561

2. Paramio MT, Izquierdo D. Current status of in vitro embryo production in sheep and goats. Reprod Domest Anim. 2014;49(Suppl 4):37-48. doi:10.1111/rda.12334

3. Lu C, Zhang Y, Zheng X, et al. Current perspectives on in vitro maturation and its effects on oocyte genetic and epigenetic profiles. Sci China Life Sci. 2018;61(6):633-643. doi:10.1007/s11427-0179280-4

4. Lonergan P, Fair T. Maturation of oocytes in vitro. Annu Rev Anim Biosci. 2016;4(1):255-268. doi:10.1146/annurev-animal-022114110822

5. Steinmann J, Buer J, Pietschmann T, Steinmann E. Anti-infective properties of epigallocatechin-3-gallate (EGCG), a component of green tea. Br J Pharmacol. 2013;168(5):1059-1073. doi:10.1111/ bph.12009

6. Huang Z, Pang Y, Hao H, Du W, Zhao X, Zhu H. Effects of epigallocatechin-3-gallate on bovine oocytes matured in vitro. AsianAustralas J Anim Sci. 2018;31(9):1420-1430. doi:10.5713/ ajas. 17.0880

7. Roth Z, Aroyo A, Yavin S, Arav A. The antioxidant epigallocatechin gallate (EGCG) moderates the deleterious effects of maternal hyperthermia on follicle-enclosed oocytes in mice. Theriogenology. 2008;70(6):887-897. doi:10.1016/j.theriogenology.2008.05.053

8. Gadani B, Bucci D, Spinaci M, Tamanini C, Galeati G. Resveratrol and epigallocatechin-3-gallate addition to thawed boar sperm improves in vitro fertilization. Theriogenology. 2017;90:88-93. doi:10.1016/j.theriogenology.2016.11.020

9. Bucci D, Spinaci M, Yeste M, et al. Combined effects of resveratrol and epigallocatechin-3-gallate on post thaw boar sperm and IVF parameters. Theriogenology. 2018;117:16-25. doi:10.1016/j. theriogenology.2018.05.016

10. Bucci D, Cunto M, Gadani B, Spinaci M, Zambelli D, Galeati G. Epigallocatechin-3-gallate added after thawing to frozen dog semen: effect on sperm parameters and ability to bind to oocytes' zona pellucida. Reprod Biol. 2019;19(1):83-88. doi:10.1016/j. repbio.2018.12.001

11. Nie JY, Zhu XX, Xie BK, et al. Successful cloning of an adult breeding boar from the novel Chinese Guike no. 1 swine specialized strain. 3 Biotech. 2016;6(2):218. doi:10.1007/s13205-016-0525-4

12. Vanderhyden BC, Caron PJ, Buccione R, Eppig JJ. Developmental pattern of the secretion of cumulus expansion-enabling factor by mouse oocytes and the role of oocytes in promoting granulosa cell differentiation. Dev Biol. 1990;140(2):307-317. doi:10.1016/00121606(90)90081-S
13. Pella R, Suárez-Cunza $\mathrm{S}$, Orihuela $\mathrm{P}$, et al. Oxidative balance in follicular fluid of ART patients of advanced maternal age and blastocyst formation. JBRA Assist Reprod. 2020;24(3):296-301. doi:10.5935/1518-0557.20200012

14. Li J, Wei H, Li Y, Li Q, Li N. Identification of a suitable endogenous control gene in porcine blastocysts for use in quantitative PCR analysis of microRNAs. Sci China Life Sci. 2012;55(2):126-131. doi:10.1007/s11427-012-4289-8

15. Okamoto A, Ikeda M, Kaneko A, Kishida C, Shimada M, Yamashita Y. The novel pig in vitro maturation system to improve developmental competence of oocytes derived from atretic non-vascularized follicle. Biol Reprod. 2016;95(4):7. doi:10.1095/ biolreprod.116.138982

16. Cetica PD, Pintos LN, Dalvit GC, Beconi MT. Antioxidant enzyme activity and oxidative stress in bovine oocyte in vitro maturation. IUBMB Life. 2001;51(1):57-64. doi:10.1080/15216540152035073

17. Spinaci M, Volpe S, De Ambrogi M, Tamanini C, Galeati G. Effects of epigallocatechin-3-gallate (EGCG) on in vitro maturation and fertilization of porcine oocytes. Theriogenology. 2008;69 (7):877-885. doi:10.1016/j.theriogenology.2008.01.005

18. Barberino RS, Santos JMS, Lins T, et al. Epigallocatechin-3-gallate (EGCG) reduces apoptosis of preantral follicles through the phosphatidylinositol-3-kinase/protein kinase B (PI3K/AKT) signaling pathway after in vitro culture of sheep ovarian tissue. Theriogenology. 2020;155:25-32. doi:10.1016/j. theriogenology.2020.05.037

19. Bresciani G, da Cruz IB, González-Gallego J. Manganese superoxide dismutase and oxidative stress modulation. Adv Clin Chem. 2015;68:87-130.

20. Pal S, Dey SK, Saha C, Tajmir-Riahi H-A. Inhibition of catalase by tea catechins in free and cellular state: a biophysical approach. PLoS One. 2014;9(7):e102460. doi:10.1371/journal.pone. 0102460

21. Espinosa-Diez C, Miguel V, Mennerich D, et al. Antioxidant responses and cellular adjustments to oxidative stress. Redox Biol. 2015;6:183-197.

22. Waiz SA, Raies-Ul-Haq M, Dhanda S, et al. Heat stress and antioxidant enzyme activity in bubaline (Bubalus bubalis) oocytes during in vitro maturation. Int $J$ Biometeorol. 2016;60(9):1357-1366. doi:10.1007/s00484-015-1129-0

23. Boumela I, Assou S, Aouacheria A, et al. Involvement of BCL2 family members in the regulation of human oocyte and early embryo survival and death: gene expression and beyond. Reproduction. 2011;141(5):549-561. doi:10.1530/REP-10-0504

24. Soto P, Smith LC. BH4 peptide derived from Bcl-xL and Bax-inhibitor peptide suppresses apoptotic mitochondrial changes in heat stressed bovine oocytes. Mol Reprod Dev. 2009;76(7):637-646. doi:10.1002/mrd.20986

\section{Publish your work in this journal}

Drug Design, Development and Therapy is an international, peerreviewed open-access journal that spans the spectrum of drug design and development through to clinical applications. Clinical outcomes, patient safety, and programs for the development and effective, safe, and sustained use of medicines are a feature of the journal, which has also been accepted for indexing on PubMed Central. The manuscript management system is completely online and includes a very quick and fair peer-review system, which is all easy to use. Visit http://www. dovepress.com/testimonials.php to read real quotes from published authors. 